\title{
PROSEDUR PEMERIKSAAN MAGNETIC RESONANCE IMAGING (MRI) BRAIN PERFUSI DENGAN METODE ARTERIAL SPIN LABELING (ASL) PADA PASIEN TUMOR
}

\author{
Novelin Safitri Maulida $^{1)}$, Edy Susanto $^{2)}$, Emi Murniati ${ }^{3)}$ \\ ${ }^{1), 2,3)}$ Health Polytechnics of Semarang-Indonesia \\ e-mail :novelinmaulida@gmail.com
}

\begin{abstract}
Background : Examination procedure of Magnetic resonance imaging (MRI) Brain Perfusion in patient with tumor disease at Radiology Department of National Brain Hospital used the MR Perfusion sequence with the Dynamic Susceptibility Contrast (DSC) method with the addition of Arterial Spin Labeling (ASL) method which was also used to determine CBF values. Nevertheless CBF values can also be obtained from the use of the DSC method. The application of these two roles in patient with tumor disease certainly has their respective roles in providing accurate information for the diagnosis. The purpose of this study was to determine the role of the application of MR perfusion with the Arterial Spin Labeling (ASL) method and the Dynamic Susceptibility Contrast (DSC) method for the diagnosis of patient with tumor disease at Radiology Department of National Brain Hospital.
\end{abstract}

Methods :The type of this research is qualitative with case study approach. The data were collected from March April 2019 at at Radiology Department of National Brain Hospital by using observation method, interview with radiology specialist doctor, sending doctor, FGD, and documentation. Data obtained from the study were analyzed by making the transcript then reduced in the form of categorization table and open coding, presented in quote form and then can be drawn conclusion.

Result : Brain perfusion MRI examination procedures in tumor patients begin with examination preparation, preparation of tools and materials, carry out the examination using the MRI Brain protocol with contrast and without contrast. The use of contrast uses the Dynamic Susceptibility Contrast (DSC) method and non-contrast use using the Arterial Spin Labeling (ASL) method where both complement each other to inform perfusion parameter values.

Conclusion : The conclution of this study indicate still needed the application of both MR perfusion methods, namely the ASL method and the DSC method. The ASL method will provide additional information in the form of absolute values of Cerebral Blood Flow that are not affected by permeability, besides that the DSC method is able to provide Cerebral Blood Volume values that are used as a parameter of Perfusion MR evaluation.

Keyword : ASL, DSC, Tumor, CBF

\section{Pendahuluan}

Magnetic Resonance Imaging (MRI) adalah suatu alat canggih di bidang kedokteran yang mengkombinasikan teknologi komputer, medan magnet tinggi $(0,064-7,0$ Tesla), dan gelombang radio untuk menghasilkan gambaran penampang tubuh manusia (Notosiswoyo, 2004). Pemeriksaan MRI mempunyai keunggulan dibandingkan modalitas pencitraan diagnostik lainnya karena menggunakan radiasi non ionisasi, bersifat non invasif, dan menghasilkan resolusi yang tinggi pada jaringan lunak serta memungkinkan pencitraan dari berbagai arah irisan pada segala bidang (transversal, sagittal, coronal, bahkan oblique) sehingga hasil gambaran lebih detail dan jelas (Kartawiguna, 2015).

Menurut Westbrook (2014) indikasi dilakukannya MRI Brain diantaranya Multiple sclerosis, infark, hemorage, infeksi, trauma, dan tumor/metastasis disease. Tumor otak merupakan penyebab kematian kedua setelah stroke dalam kelompok penyakit neurologis. Menurut komite penanggulangan kanker Nasional, tumor otak meliputi sekitar $85-90 \%$ dari seluruh kanker susunan saraf pusat. Tumor susunan saraf 
pusat ditemukan sebanyak $\pm 10 \%$ dari neoplasma seluruh tubuh, dengan frekuensi $80 \%$ terletak pada intracranial dan 20\% di dalam kanalis spinalis (Enggariani, 2008).

Tumor merupakan pertumbuhan serta akumulasi dari sel-sel abnormal yang disebabkan dari mutasi sel. Tumor otak merupakan salah satu bagian dari tumor pada system saraf, disamping tumor spinal dan tumor perifer. Tumor otak ini dapat berupa tumor yang bersifat primer ataupun yang merupakan metastasis dari tumor pada organ lainnya (Wahjoepramono, 2006).

Menurut World Health Organization (WHO) meningioma adalah tumor otak primer yang berasal dari sel meningothelial (arachnoid) leptomeningen. Tumor ini dapat terjadi dimana saja sepanjang lokasi sel arachnoid, biasanya menempel pada permukaan dalam duramater dan umumnya tumbuh lambat (Saraf, 2011). Meningioma adalah tumor otak primer yang paling sering didiagnosa yaitu sebesar 33,8\% dari seluruh tumor otak primer. Di Amerika Serikat, insiden meningioma yang dikonfirmasi dengan pemeriksaan patologi diperkirakan sebesar 97,5 per 100.000 jiwa. Namun jumlah ini diperkirakan lebih rendah dari yang sebenarnya karena adanya sebagian meningioma yang tidak dioperasi. Sedangkan di Inggris, insiden meningioma diperkirakan sebesar 5,3 per 100.000 jiwa dan tetap stabil selama 12 tahun ini (Wiemels, 2010; Cea -Soriano, 2012). Di Indonesia data tentang insiden tumor susunan saraf pusat setiap tahunnya belum dilaporkan. Beberapa data yang ada mengenai frekuensi tumor otak umumnya didasari atas pengalaman pribadi para dokter bedah saraf, hasil otopsi, dan angka angka dari beberapa rumah sakit (Rengachary, 2005). Di Indonesia insiden tumor intracranial pada orang dewasa terjadi pada usia 30-70 tahun dengan puncak usia 40-65 tahun (Enggariani, 2008).

Pada bidang radiologi, diagnosis terbaik pada tumor intracranial adalah dengan melakukan pemeriksaan MRI Brain. MRI harus menjadi pemeriksan pertama pada pasien dengan tanda dan gejala kelainan pada intracranial. Sekuen rutin pada pemeriksaan MRI Brain kasus tumor yakni SE/FSE/Incoherent (spoiled) GRE T1, SE/FSE PD/T2, FLAIR, dan Diffusion Weighted Imaging (Westbrook, 2014). Menurut Elmaoglu (2012) sekuen-sekuen standar yang dapat dilakukan untuk pemeriksaan MRI Brain pada kasus tumor yaitu Axial T1 Spin Echo, T2 Fast Recovery Fast Spin Echo, T2 FLAIR, Coronal T1 dan T1 axial post contrast injection, T1 Coronal serta T1 sagital. Sekuen tambahan yang dapat digunakan untuk mendiagnosa tumor otak antara lain axial gradient Recalled Echo (GRE), Axial Diffusion Weighted Imaging (DWI), Magnetic Resonance Angiography, serta magnetic resonance spectroscopy (Westbrook,2014). Pembobotan T1 berfungsi untuk menunjukan perbedaan anatomi antara grey matter dan white matter, pembobotan $\mathrm{T} 2$ berfungsi untuk menunjukan patologi pada brain serta sekuen FLAIR digunakan untuk memvisualisasi jaringan-jaringan yang berada di dekat cerebro spinal fluid (CSF). DWI dan DTI (Diffusion Tensor Imaging) merupakan urutan pencitraan resonansi magnetic advanced fungsional, yang telah banyak digunakan untuk mengevaluasi tumor intracranial. DWI mampu melihat kerusakan jaringan berdasar difusi jaringan pada otak. MRA akan memvisualisasikan dengan baik vaskularisasi pada otak (Westbrook, 2014).

Menurut Ferre, dkk (2013), penggunaan sekuen perfusi pada MRI mampu memberikan informasi fungsional jaringan mengenai karakteristik lesi dan prognosis pada beberapa patologi khususnya untuk melihat Cerebral Blood Flow (CBF). Untuk menghasilkan nilai CBF biasanya akan digunakan metode metode dalam MR Perfusi. Pencitraan MRI Brain Perfusi dapat dilakukan dengan tiga metode yaitu Dynamic Susceptibility Contrast (DSC), Dynamic Contrast Enhanced (DCE), dan Arterial Spin Labeling (ASL). Untuk menghasilkan citra CBF biasanya digunakan metode DSC, dimana metode ini akan menghasilkan beberapa parameter perfusi Cerebral Blood Flow (CBF), Cerebral Blood Volume (CBV), dan Mean Transit Time (MTT) dengan prosedur penginjeksian media kontras gadolinium dengan flow rate tertentu ke dalam tubuh pasien. Metode DSC ini masuk kedalam kategori teknik invasive karena diperlukan injeksi media kontras untuk menghasilkan perfusi pada jaringan. Metode ini tergantung pada waktu relaksasi $\mathrm{T} 2$ atau $\mathrm{T} 2 *$, kemudian metode DCE adalah metode lain yang berbasis kontras eksogen. Metode ini tergantung pada waktu relaksasi T1, sedangkan metode Arterial Spin Labelling (ASL) adalah metode yang berbasis endogen, bersifat non invasif, dan tidak menggunakan media kontras (Jahng dkk, 2014). Menurut Jeffrey M Pollock, MD, dkk (2009) dikembangkan teknik ASL pada pemeriksaan MRI Brain untuk mengetahui perfusion cerebral blood flow tanpa menggunakan media kontras.

Arterial Spin Labeling (ASL) adalah metode perfusi MRI tanpa menggunakan media kontras sehingga cocok untuk pasien yang memiliki riwayat gagal ginjal. Metode ini menggunakan media kontras endogen berupa spins atom hidrogen dalam darah yang menuju jaringan (Martirosian dkk, 2010). Metode ini memperlihatkan oksigenisasi dalam pembuluh darah dan cerebral blood flow (CBF) (Woodward, 2001).

Berdasarkan studi pendahuluan, pada pasien dengan tumor otak MR Perfusi menjadi salah satu modalitas yang sangat sensitif untuk mendeteksi adanya ketidaknormalan. Saat ini, DSC menjadi salah satu metode yang sering digunakan untuk mengevaluasi adanya hypoperfusi pada tumor. Namun, DSC membutuhkan adanya media kontras gadolinium yang mana tidak semua pasien mampu menggunakannya karena kontra indikasi tertentu sehingga digunakanlah alternatif untuk melakukan MR Perfusi yaitu metode ASL. Melalui observasi dan pengamatan oleh peneliti di Rumah Sakit Pusat Otak Nasional menggunakan sekuen DSC dan ASL secara bersamaan dalam pemeriksaan MRI Perfusi, dimana kedua sekuen ini memiliki fungsi yang sama pada MR Perusi. Walaupun demikian ASL merupakan salah satu metode advance atau lanjut pada pemeriksaan MRI Brain yang peneliti temui pada saat melakukan studi pendahuluan di RS Pusat Otak Nasional. Dengan banyaknya MRI berkekuatan > 3T membuat metode ASL berubah dari sebuah metode penelitian dan pengembangan kini sudah digunakan 
untuk diagnosa klinis (Petersen dkk, 2006). Pelabelan darah pada ASL menggunakan proton pada airsebagai media kontras endogen. Kelebihan dari metode ASL adalah nonivasif, pengukuran dari cerebral blood flow (CBF) yang lebih sensitif, tidak memerlukan media kontras, dan dimungkinkan untuk melakukan pengukuran berulang (Wolf dan Detre, 2007).Namun demikian ASL menghasilkan nilai SNR yang rendah, labeling inefficiency, dan membutuhkn waktu yang lama (Pungavkar dan Rama,2017). Pada beberapa tahun terakhir, metode ASL menjadi alternatif dalam menunjang pemeriksaan CT dan MR perfusi untuk mempelajari mekanisme otak pada klinis tumor. Selain itu, dengan kelebihan ASL tidak menggunakan media kontras dan noninvasive membuat ASL lebih baik daripada pemeriksaan MR perfusi dengan metode DSC untuk mengevaluasi tumor otak (Pungavkar dan Rama,2017). Dalam hal ini, penulis tertarik untuk mengimplementasikannya dalam penelitian untuk mengetahui prosedur dan peranan dari penerapan MR Brain Perfusi dengan metode ASL dan DSC ini dengan judul "Prosedur Pemeriksaan MRI Brain Perfusi Dengan Metode Arterial Spin Labeling (ASL) Pada Pasien Tumor".

\section{Metode}

Jenis penelitian ini adalah penelitiankualitatif dengan pendekatan studi kasus. Subyek penelitian ini adalah 3 pasien dengan permintaan pemeriksaan MRI Brain Kontraspadapasien 1 dan MRI Brain Kontras + MRS padapasien 2 dan 3 . Pasien 1 denganklinis meningioma residif, Pasien 2 denganklinismeningioma post Operasi 6 bulan yang lalu, danPasien 3 denganklinismeningioma.Adapunsubjekpenenilitianiniyaitu, 5 radiografer, 2 dokter spesialis radiologi dan 1 dokter pengirim.Lokasipenelitianiniadalah di Instalasi Radiologi Rumah Sakit Pusat Otak Nasional danwaktupenelitianyakniMaretsampaidenganApril

2019..Metodepengambilan data dengancaraobservasi, wawancara, Focus Group Discussion (FGD)dandokumentasi. Data dianalisissecaradeskriptif. Instrumen penelitian yang digunakanyakni :

1. Pedoman observasi

2. Pedoman wawancara dengan dokter spesialis radiologi

3. Pedoman wawancara dengan dokter pengirim

4. Pedoman Focus Group Discussion (FGD) dengan radiografer

5. Pedoman dokumentasi.

\section{Hasil dan Pembahasan}

1. Paparan Kasus

Penelitianinimenggunakan pasiendenganidentitasmasing-masingyaitu : pasien 1 dengan namapasienNn. V, umur21 Tahun, permintaanfoto MRI Brain+Kontras,jenis kelamin Perempuan, tanggal pemeriksaan 10April 2019, diagnosa Meningioma residif, pasien 2 dengan namapasienNy. K, umur37 Tahun, permintaanfoto MRI Brain Kontras + MRS, jenis kelamin Perempuan, tanggal pemeriksaan 9April 2019, diagnosa Meningioma posy OP 6 bulan yang lalu,kemudianpasien 3 dengan namapasienTn.Y, umur31 Tahun, permintaanfoto MRI Brain Kontras + MRS,jenis kelamin Laki-laki, tanggal pemeriksaan 19Maret 2019, diagnosa Meningioma.

2. RiwayatPasien

Pasien 1 merasakan keluhan keluhan sering kebas pada bagian kiri, pasien 2 merasakan keluhan nyeri kepala, serta penglihatan sebelah kanan sering kabur, danpasien 3 kepala sering nyeri dan berat, pendengaran sedikit terganggu.

3. Prosedur pemeriksaan MRI Brain Perfusi pada pasien tumor dengan metode ASL dan DSC di Instalasi Radiologi Rumah Sakit Pusat Otak Nasional

Persiapan pasien pada pemeriksaan MRI brain perfusipada pasien tumor di Instalasi Radiologi Rumah Sakit Pusat Otak Nasional, sebelum pemeriksaan dilakukan pasien terlebih dahulu cek laboratorium meliputi cek ureum dan kreatinin untuk kemudian akan dilakukan penghitungan GFR oleh petugas radiologi. Pada saat melakukan pengecekan pasien dipastikan dalam kondisi puasa 2 jam sebelum pemeriksaan. Kemudian pasien diberikan penjelasan mengenai pemeriksaan yang akan dilakukan dan kemudianskrining mengenai riwayat pasien seperti berat badan pasien, riwayat dilakukannya operasi, riwayat dilakukannya pemeriksaan CT-Scan dan MRI, apakah pasien sedang menggunakan benda-benda berbahan logam di dalam tubuh, dan apa yang dirasakan dan dikeluhkan.

Peralatan: Alat dan bahan yang digunakan pada pemeriksaan MRI Siemens Skyra 3T, Head coil 20 channel, headphone dan fiksasi, system console MRI, monitor CCTV, selimut, printer, spuit $20 \mathrm{cc}$, needle 18, alcohol swab, dan media kontras (Gadovist $1.0 \mathrm{mmol} / \mathrm{mL}$ sebanyak $10 \mathrm{cc}$ ).

Teknikpemeriksaan MRI brain kontrasdanbrain kontras + MRSdengan Klinis Meningioma residif, meningioma post $O P \quad 6$ bulan yang laludanklinismeningioma di Instalasi Radiologi RumahSakitPusatOtakNasional yaitupasien diposisikan supine diatas meja pemeriksaan (head first), kepala diposisikan di dalam head coil dan diberi headphone guna meredam suara dari pesawat MRI, serta berikan fiksasi pada kepala pasien agar posisi kepala pasien dalam keadaan nyaman. Posisikan lengan pasien berada di samping kanan dan kiri dan beri selimut kepada pasien. Atur posisi objek pada pertengahan gantry dengan mengatur sinar laser horizontal sejajar kedua alis pasien dan sinar laser vertical sejajar dengan MSP kepala pasien sehingga sentrasi tepat berada pada glabella pasien.

Kemudian tahap selanjutnya adalah input data pasien pada workstation MRI seperti : nama pasien, nomor RM, nomor MRI, tanggal lahir pasien, jenis kelamin, umur, berat badan, inisial operator dan 
jenis pemeriksaan yang dilakukan. Protokol yang digunakan pada pasien Nn.V menggunakan protokol pemeriksaan MRI brain kontras sedangkan pada Ny.K dan Tn.Y protokol MRI brain kontras ditambah dengan protokol MR Spectroscopy.Hasil citra pada masing-masing sekuen diantaranya sebagai berikut:

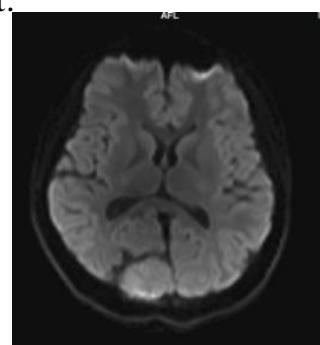

(a)

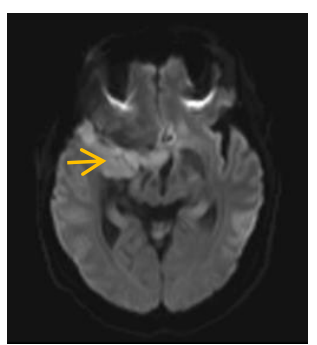

(b) (a) Sekuen DWI Pasien 1 menampakan adanya infark dengan gambaran deep white matter di bagian posterior parietal kiri (b) Sekuen DWI Pasien 2 tampak adanya restricted area di inferolateral kiri

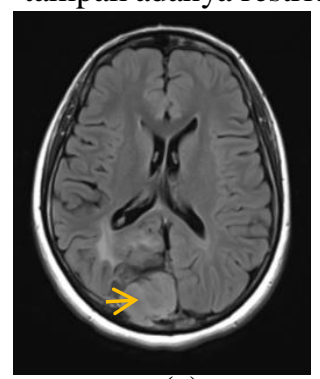

(a)

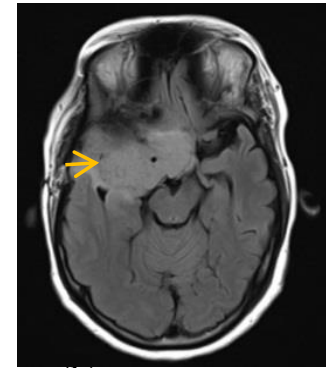

(b) (a) Sekuen FLAIR Pasien 1 tampak lesi hiperintens di posterior parietal kiri (b) Sekuen FLAIR Pasien 2 tampak massa meluas ke intrasella

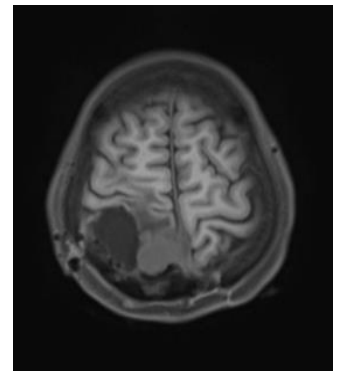

(a)

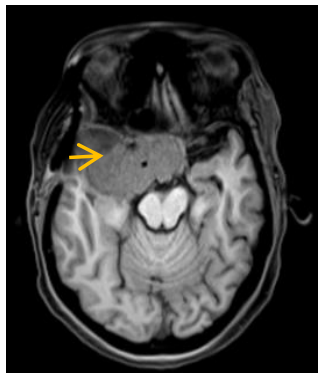

(b) (a) Sekuen T1 Axial Pasien 1 tampak lesi hipointens di posterior parietal kiri (b) Sekuen T1 Axial Pasien 2 tampak massa hipointens di inferolateral kiri

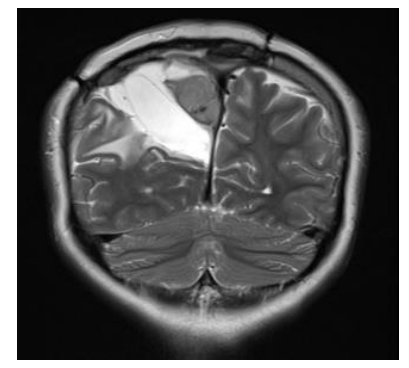

Sekuen T2 Coronal Pasien 1 tampak lesi hiperintens di lobus kiri

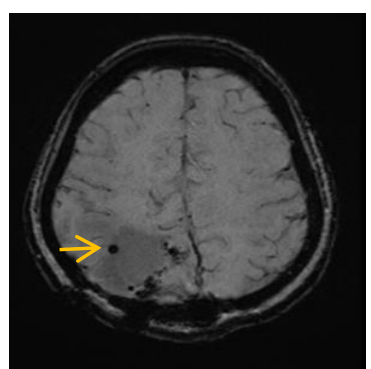

Sekuen SuscaptibilityWeightedImaging Pasien 1 tampak adanya microbleed di posterior parietal kiri

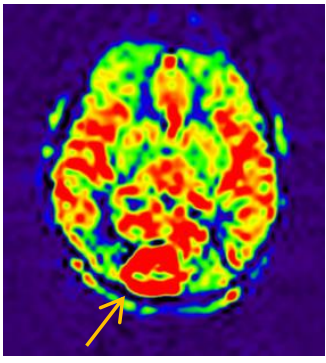

(a)

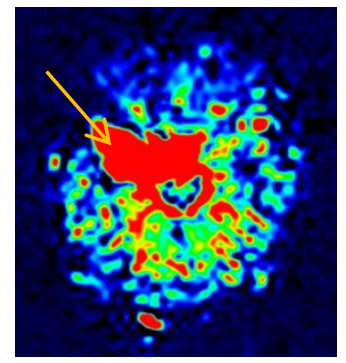

(b) (a) Sekuen ASL Pasien 1 nampak peningkatan CBF pada area tumor (b) Sekuen ASL Pasien 2 tampk peningkatan $\mathrm{CBF}$ di area tumor

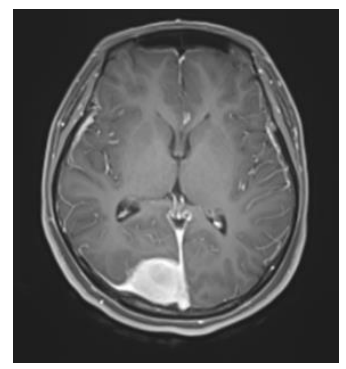

Sekuen T1 Axial + C Pasien 1 tampak penyengatan difus di posterior parietal kiri

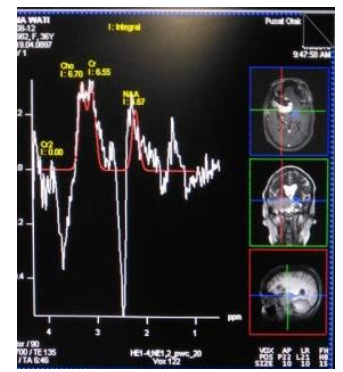

(a)

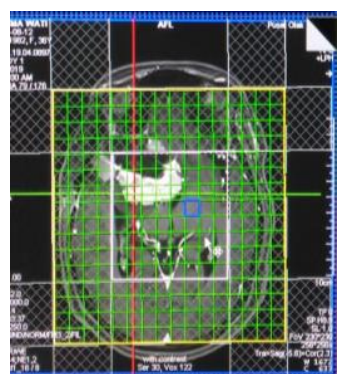

(b) (a) grafik matebolit spektroskopi pasien Ny.K (b) Multi Voxel Spectroscopy pasien Ny.K

Proses filming di Instalasi Radiologi RumahSakitPusatOtakNasional untuk MRI BrainPerfusi 
pada pasien tumormenggunakanfilm yang dicetak berjumlah 4 lembardan $1 \mathrm{CD}$.

4. Peranan dari penerapan MR Perfusi dengan metode Arterial Spin Labelling (ASL) dan metode Dynamic Susceptibility Contrast (DSC) dalam penegakan diagnosa tumordi Rumah Sakit Pusat Otak Nasional

Dalam pemeriksaan MRI Perfusi untuk pada pasien tumor terdapat beberapa sekuen yang digunakan di Instalasi Radiologi Rumah Sakit Pusat Otak Nasional, sekuen-sekuen tersebut tentunya saling melengkapi sesuai permintaan dokter radiolog. Untuk pasien tumor sendiridilakukan perfusi dengan kontras dan perfusi tanpa kontras.Sekuen MR Perfusi tanpa kontras yang digunakan dalam pemeriksaan MRI Brain pada tumor di Instalasi Radiologi Rumah Sakit Pusat Otak Nasional adalah 3D ASL. ASL ini merupakan metode perfusi tanpa kontras yang lebih aman karena ionisasi dan no contrast agent, mudah karena tanpa persiapan khusus pada pasien dan pemeriksaannya juga lebih cepat dan mampu menilai perfusi pada jaringan lunak. Walaupun menghasilkan SNR yang rendah. Sekuen ini digunakan untuk melihat grafik Cerebral Blood Flow (CBF) pada pasien.Untuk mendiagnosa tumor, metode yang lebih baik digunakan yaitu metode perfusi kontras daripada ASL.ASL memiliki kelebihan dari sekuen perfusi kontras karena apabila menggunakan perfusi kontras grafik CBF yang dihasilkan kurang baik. Karena dengan metode perfusi kontras di Instalasi Radiologi Rumah Sakit Pusat Otak Nasional menggunakan injeksi manual dimana flow rate yang dihasilkan tergantung dengan kekuatan perawat dalam menginjeksikan. Pada perfusi kontras (DSC) diperoleh data lebih lengkap mengenai $\mathrm{CBF}, \mathrm{CBV}$, dan yang lain sebagainya selain itu pemeriksaan ASL belum reliable dan belum terstandarisasi bahkan masih jarang rumah sakit yang menggunakan sekuen tersebut.

Walaupun demikian pemeriksaan MRI yang menjadi gold standar untuk kasus tumor adalah MRI dengan menggunakan kontras. Karena dengan MRI kontras dapat membedakan batas tumor dengan batas edema. Dengan adanya kontras maka akan bisa mengevaluasi adanya pendarahan atau tidak, ada tidaknya kalsifikasi, mengevaluasi jenis tumor ganas atau jinak. Selain itu bisa juga membedakan adanya suatu metastase atau hanya proses infeksi saja.

Metode ASL dinilai oleh radiolog mampu memberi informasi tambahan dengan nilai Cerebral Blood Flow (CBF) yang lebih baik daripada metode Dynamic Susceptibility Contrast yang bergantung dengan tekanan dan teknik penyuntikan.Walaupun demikian peran metode ASL sendiri dalam pencitraan diagnostik pada pemeriksaan MRI Brain Perfusi pasien tumor bagus untuk melihat vaskularisasi dan mempermudah dalam melihat grafik CBF. ASL juga menggunakan basic sekuen FSE yang cepat dan sensitif terhadap susceptibility (pendarahan) sehingga lebih akurat untuk melihat vaskularisasi pada tumor.
1. Prosedur pemeriksaan MRI Brain Perfusi pada pasien tumor dengan metode ASL dan DSC di Instalasi Radiologi Rumah Sakit Pusat Otak Nasional

Pemeriksaan MRI brain pada pasien tumor dilakukan pada tiga pasien dengan klinis tumor mengioma residif, tumor meningioma post OP 6 bulan yang lalu dan meningioma.

a) PersiapanPasien

Persiapan pasien pada pemeriksaan MRI brain perfusipada pasien tumor di Instalasi Radiologi Rumah Sakit Pusat Otak Nasional, sebelum pemeriksaan dilakukan pasien terlebih dahulu cek laboratorium meliputi cek ureum dan kreatinin untuk kemudian akan dilakukan penghitungan GFR oleh petugas radiologi. Pada saat melakukan pengecekan pasien dipastikan dalam kondisi puasa 2 jam sebelum pemeriksaan. Kemudian pasien diberikan penjelasan mengenai pemeriksaan yang akan dilakukan dan kemudian dilakukan skrining mengenai riwayat pasien seperti berat badan pasien, riwayat dilakukannya operasi, riwayat dilakukannya pemeriksaan CT-Scan dan MRI, apakah pasien sedang menggunakan bendabenda berbahan logam di dalam tubuh, dan apa yang dirasakan dan dikeluhkan.

Kemudian pasien menanggalkan benda-benda logam atau alat elektronik yakni jam tangan, ATM, kartu kredit, kunci dan ikat pinggang dan disimpan pada tempat yang telah disediakan. Pasien diharuskan mengganti baju dengan baju yang sudah disediakan untuk pasien. Selanjutnya, pasien dipersilahkan untuk buang air kecil (BAK) sebelum dilakukan pemeriksaan karena waktu pemeriksaan yang membutuhkan waktu lama dan ruang pemeriksaan yang dingin, sehingga pasien akan merasa nyaman selama pemeriksaan berlangsung

Menurut responden Radiografer, persiapan pasien pada MRI brain diawali dengan puasa 2 jam sebelum pemeriksaan dilakukan baik pada pasien yang pada pemeriksaannya menggunakan media kontras ataupun tanpa menggunakan media kontras. Selanjutnya pada pasien dengan pemeriksaan kontras, pasien diminta untuk cek ureum dan kreatinin untuk melihat fungsi ginjal. Setelah itu, sebelum pemeriksaan dilakukan pasien diharuskan mengganti baju dan melepas semua aksesories yang ada pada tubuh pasien yang berbahan metal seperti elektronik juga diharuskan untuk disimpan. Kemudian pasien dilakukan skrining tentang riwayat pasien. Selanjutnya sebelum pemeriksaan dimulai, pasien dianjurkan untuk buang air kecil terlebih dulu dikarenakan pemeriksaan menggunakan waktu yang cukup lama.

Menurut Moeller dan Reif (2010), persiapan pasien dilakukan dengan cara mempersilakan pasien 
untuk buang air kecil ke toilet sebelum pemeriksaan dimulai, menjelaskan prosedur pemeriksaan kepada pasien, memberikan pasien head phone, meminta pasien untuk menanggalkan pakaian kecuali untuk pakaian dalam (hanya di atas pinggang), dan meminta pasien untuk melepas semua yang mengandung logam (arloji, perhiasan, alat bantu dengar, jepit rambut, perhiasan, dll.).

Menurut westbrook (2014) screening pasien merupakan salah satu tindakan keperawatan dan keamanan pada pasien agar terwujud keselamatan pada pasien. Untuk memastikan keamanan pada pasien maka dilakukan screening sebelum pasien memasuki ruang MRI, screening dilakukan dengan mengisi checklist yang isisnya antara lain seputar riwayat pasien, apakah pasien menderita claustrophobia, apakah pasien menggunakana pacemaker, apakah pasien menggunakan klip aneurysme. Kemudian melakukan check pada tubuh apakah ada benda logam contohnya perhiasan, jam tangan, anting dan aksesoris tubuh berbahan logam yang melekat pada tubuh.

Menurut penulis persiapan pasien untuk pemeriksaan MRI brain di Instalasi Radiologi Rumah Sakit Pusat Otak Nasional sudah cukup sesuai dengan teori. Persiapan pasien di lapangan maupun di Moeller dan Reif (2010) hampir sama. Pasien dijelaskan mengenai prosedur pemeriksaan dan meminta pasien untuk melepas semua benda yang berbahan logam. Selain itu, persiapan yang dilakukan pada pasien untuk pemeriksaan MRI Brain dengan kasus tumor otak di Instalasi Radiologi Rumah Sakit Pusat Otak Nasional dengan teori yang disampaikan oleh westbrook (2014) tidak jauh berbeda. Khususnya pada screening pasien baik pada teori maupun pada pelaksanaan di Rumah Sakit keduanya menggunakan check list untuk melakukan screening terhadap logam baik terdapat dalam tubuh pasien (jam tangan, anting,dsb). Hal ini bertujuan untuk mewujudkan keselamatan dan kenyamanan pada pasien saat pemeriksaan.

b) Persiapan Alat dan Bahan

Persiapan alat dan bahan pada pemeriksaan MRI brain perfusimenggunakan pesawat MRI Siemens Skyra 3T, Head coil 20 channel, headphone dan fiksasi, system console MRI, monitor CCTV, selimut, printer, spuit $20 \mathrm{cc}$, needle 18 , alcohol swab, dan media kontras (Gadovist $1.0 \mathrm{mmol} / \mathrm{mL}$ sebanyak 10 cc).

Pencitraan diagnostik diperlukan untuk deteksi dan terapi tumor. Pencitraan diagnosik standar untuk tumor otak adalah Magnetic Resonance Imaging (MRI) dengan media kontras Gadolinium (Laszlo,2009).

Menurut dokter pengirim, dengan menggunakan media kontras akan nampak ukuran tumor dengan baik, batas tumor dan batas edema akan lebih tegas, dan MRI brain dengan kontras menjadi salah satu goal standar apalagi untuk mengioma yaitu jenis tumor dengan banyak vaskularisasi. Pemeriksaan dengan kontras dapat efektif dalam membantu menegakan diagnosa.

Menurut penulis, walaupun MRI brain perfusi dengan kontras menjadi gold standar akan tetapi pemeriksaan ini tidak dapat dilakukan pada semua pasien khususnya pasien dengan klinis gagal ginjal. Oleh karena itu dibutuhkan alternatif metode baru untuk menunjang diagnosa sebagai tambahan informasi. Karena pada kenyataannya pemeriksaan dengan DSC memang memiliki keuntungan mampu menilai parameter MR Perfusi dengan lebih lengkap.

c) PosisiObjek

Setelah dilakukan persiapan, pasien masuk kedalam ruang MRI. Kemudian pasien diposisikan supine diatas meja pemeriksaan (head first), kepala diposisikan di dalam head coil dan diberi headphone guna meredam suara dari pesawat MRI, serta berikan fiksasi pada kepala pasien agar posisi kepala pasien dalam keadaan nyaman. Posisikan lengan pasien berada di samping kanan dan kiri dan beri selimut kepada pasien. Atur posisi objek pada pertengahan gantry dengan mengatur sinar laser horizontal sejajar kedua alis pasien dan sinar laser vertical sejajar dengan MSP kepala pasien sehingga sentrasi tepat berada pada glabella pasien.

Menurut Westbrook (2014) posisi pasien pemeriksaan MRI Brain yaitu pasien supine diatas meja pemeriksaan, dan kepala pasien berada pada head coil. Atur kepala pasien sehingga interpuppilary line sejajar dengan meja pemeriksaan. Posisikan pasien agar lampu indicator longitudinal sejajar dengan pertengahan tubuh pasien, dan lampu indicator horizontal melewati nasion. Beri alat fiksasi pada pasien agar selama pemeriksaan pasien tetap tenang dan nyaman.

Menurut penulis titik sentrasi pada pasien sudah dilaksanakan sesuai SOP. Pengaturan titik sentrasi di Instalasi Radiologi Rumah Sakit Pusat Otak Nasional sudah sesuai dengan teori. Dimana menurut penulis titik sentrasi dan posisi objek harus tetap diperhatikan.

Pemeriksaan MRI brain perfusi di Instalasi Radiologi Rumah Sakit Pusat Otak Nasional menggunakan penambahan sekuen perfusi dengan metode Arterial Spin Labeling (ASL) hal ini membuat posisi objek sangat penting untuk diperhatikan. Posisi objek diatur true AP dan simetris dengan menambahkan fiksasi di sekitar objek untuk mengurangi pergerakan pasien.

Menurut Grade (2015), Tujuan ASL adalah penilaian tingkat perfusi jaringan, yang sangat berbeda dari aliran darah makrovaskuler. Perfusi jaringan, atau pertukaran air dan nutrisi dengan jaringan, terjadi di sepanjang kapiler. ASL pada dasarnya 'mengikuti' molekul air darah dari kompartemen arteri sampai ke 
lapisan kapiler jaringan, menggunakannya sebagai pelacak difusible. ASL mudah dilakukan oleh inversi atau saturasi magnetisasi di sepanjang sumbu $\mathrm{Z}$ molekul darah di arteri. Bagian dari akuisisi ASL ini disebut pelabelan.

Menurut responden Radiografer, pasien diposisikan supine diatas meja pemeriksaan dengan kedua lengan disamping tubuh. Pasien menggunakan head coil. Posisi kepala pasien diusahakan true AP dan simetris. Fiksasi di tambahkan untuk meminimalisir pergerakan pada pasien. Posisi objek harus tetap diam karena akuisisi citra dilakukan dua kali dan kebanyakan menggunakan gradient $\mathrm{Z}$ dimana akan dilakukan pelabelan terus menerus pada gradient terebut.

Menurut penulis selama dilakukannya pemeriksaan ASL posisi objek selalu diperhatikan oleh radiografer di Rumah Sakit Pusat Otak Nasional. Hal ini dikarenakan posisioning objek dalam hal ini objek yang dimaksud adalah kepala juga menentukan hasil dari ASL. Pada metode ini kita tidak bisa melakukan penyudutan untuk mensimetriskan area yang akan dilakukan scanning sehingga posisi yang baik akan menghasilkan grafik yang baik pula.

Kemudian tahap selanjutnya adalah input data pasien pada workstation MRI seperti : nama pasien, nomor RM, nomor MRI, tanggal lahir pasien, jenis kelamin, umur, berat badan, inisial operator dan jenis pemeriksaan yang dilakukan. Protokol yang digunakan pada pasien $\mathrm{Nn} . \mathrm{V}$ menggunakan protokol pemeriksaan MRI brain kontras sedangkan pada Ny.K dan Tn.Y protokol MRI brain kontras ditambah dengan protokol MR Spectroscopy.

d) Protokolpemeriksaan

Pemeriksaan MRI Brain perfusi pada pasien tumor dilakukan dengan menggunakan protokol MRI Brain kontras dengan metode Dynamic Susceptibility Contrast (DSC) ditambah dengan penggunaan sekuen MR perfusi metode Arterial Spin Labelling (ASL). Sekuen dalam protokol tersebut yaitu Localizer, FLAIR, DWI, T1 Axial, T2 Coronal, SWI, ASL, DSC, T2 Axial + C, dan T1 axial + C. Pada pasien 2 dan 3 ditambah satu sekuen tambahan yaitu MR Spectroscopy. Pada protokol pemeriksaan sekuensekuen yang digunakan sudah mampu dalam menegakan diagnose tumor. Namun banyaknya sekuen membuat waktu pemeriksaan menjadi lama. Satu pemeriksaan MRI Brain dengan menggunakan protokol MRI Brain kontras dapat memakan waktu kurang lebih 30 menit dan apabila ditambahn dengan MRS akan menambah waktu kurang lebih 5 menit. Hal tersebut belum ditambah dengan persiapan pasien dan injeksi media kontras.

Menurut responden radiografer, sekuen yang digunakan untuk pemeriksaan MRI brain perfusi untuk pasien tumor yaitu sekuen brain rutin ditambah dengan penyuntikan kontras dan perfusi tanpa kontras dengan metode Arterial Spin Labeling sesuai dengan permintaan dokter radiolog.

Menurut Elmaouglu (2012) sekuen standar yang digunakan pemeriksaan MRI brain dengan kasus tumor otak yaitu Axial T1, T2, T2 FLAIR,Coronal T1, serta sagittal T1 Post injection axial T1, coronal t1, dan sagittal t1. Kemudian westbrook (2014) menambah sekuen-sekuen tambahan yang dapat digunakan pada klinis tumor otak antara lain Axial GRE yang dilakukan apabila kelainan yang terjadi disertai dengan pendarahan, DWI untuk melihat restricted diffusion area pada otak serta MR Angiography yang dilakukan dengan tujuan untuk melihat pembuluh darah yang berada disekitar tumor yang dicurigai sebagai feeding artery. MR Spectroscopy yang dilakukan dengan tujuan untuk melihat konsentrasi metabolit pada tumor sehingga dapat membantu dan menentukan jenis serta grade tumor.

Menurut penulis, protokol pemeriksaan MRI Brain kontras yang dilakukan di Instalasi Radiologi Rumah Sakit Pusat Otak Nasional sudah optimal untuk lamanya waktu memang dikarenakan walaupun sekuen yang digunakan relative banyak akan tetapi saling mendukung dan mempermudah dokter radiologi dalam menegakan diagnose. Akan tetapi terdapat sekuen dengan fungsi yang relative hamper sama yaitu protokol MRI Perfusi dengan kontras (dynamic susceptibility contrast ) dan juga menggunakan protokol perfusi tanpa kontras (Arterial Spin Labelling). Perbedaan kedua sekuen ini tentunya dengan penggunaan media kontras yang di aplikasi pada pasien. Kedua protokol ini akan menghasilkan nilai cerebral blood flow yang digunakan diperlukan untuk mendiagnosa pasien tumor.

Pada tahap scanning terdapat terdapat dua tahap yaitu pre contrast dan tahap post contrast. Sekuen yang dilakukan pada tahap pre contrast antara lain localizer, FLAIR, DWI, T1 Axial, T2 Coronal, SWI, dan ASL. Kemudian sekuen yang dilakukan pada tahap post contrast antara lain DSC, T2 Axial+ C, T1 Axial + C, T1 Sagital + C, dan T1 coronal + C. injeksi media kontras dilakukan pada saat dilakukan scanning sekuen DSC, media kontras yang digunakan adalah media kontras positif dengan merk dagang Gadovist $1.0 \mathrm{mmol} / \mathrm{mL}$ sebanyak $10 \mathrm{cc}$. injeki dilakukan melalui intravena dengan IV line yang telah terpasang pada pasien saat melakukan persiapan dan dilakukan secara manual.

Menurut Food and Drugs Administration (FDA) (2010), dosis yang direkomendasikan untuk gadovist 1.0 adalah $0.1 \mathrm{~mL} / \mathrm{kg}$ berat badan $(0.1 \mathrm{mmol} / \mathrm{kg})$, Gadovist 1.0 dapat di injeksikan secara intravena baik secara manual atau dengan menngunakan injector. Pembilasan dengan menggunakan larutan saline setelah injeksi sangat direkomendasikan. 
Menurut penulis terdapat perbedaan dalam penggunaan dosis media kontras, penggunaan dosis media kontras di Instalasi Radiologi Rumah Sakit Pusat Otak Nasional sebanyak $10 \mathrm{cc}$ (satu spuit). Apabila dosis yang digunakan dihitung dengan melihat berat badan masing-masing pasien maka dosis media kontras yang digunakan pada pemeriksaan adalah dua kalinya. Hal tersebut dilakukan pada pasien Nn.V dengan tujuan agar patologis terlihat lebih jelas (enhance) sehingga apabila patologis tidak terlihat karena kurang enhance, tidak akan dilakukan pengulangan scanning dengan menambah media kontras yang berakibat waktu pemeriksaan akan lebih lama. Selain itu menurut Alisson, $\operatorname{dkk}(2007)$ penggunaan double dose media kontras gadolinium untuk orang dewasa diperbolehkan selama tidak lebih dari lethal dose yang disarankan $(8 \mathrm{mmol} / \mathrm{kgBB})$.

Tahap terakhir adalah melakukan filming. Film yang digunakan pada pemeriksaan MRI Brain pada kasus tumor otak dengan kontras sebanyak 4 lembar ukuran $35 \times 43 \mathrm{~cm}$ ditambah dengan $1 \mathrm{CD}$ berisi file hasil MRI pasien. Citra yang dicetak pada lembar film yaitu T1 Axial Film, T1 Axial post kontras, T1 Sagital post kontras dan T1 coronal post kontras.

Menurut penulis jumlah film yang digunakan sudah cukup untuk mewakili seluruh citra dalam menampilkan informasi patologis pada pasien. Apalagi ditambah dengan adanya CD yang berisi file hasil MRI pasien yang akan lebih memudahkan dokter dalam membaca hasil citra dan kemudahan memberikan informasi pada dokter. Penggunaan film dalam menampilkan citra pemeriksaan MRI brain sudah dilakukan sesuai dengan SOP yang berlaku di rumah sakit.

Menurut penulis sekuen pemeriksaan MRI brain perfusidi Instalasi Radiologi Rumah Sakit Pusat Otak Nasional sudah cukup sesuai dengan Elmaoglu (2012) dan Westbrook (2014) sekuen yang digunakan sangat lengkap yaitu scanning pre kontras dan post contrast dimana setiap sekuen memiliki fungsi masing masing dan tambahan sekuen MR Perfusi non kontras dengan metode ASL menjadi informasi tambahan sesuai dengan permintaan dokter radiolog. Setiap pasien dengan kasus tumor dilakukan dengan menggunakan sekuen yang sama. Baik pre maupun pasca operasi pasien dilakukan pemeriksaan MRI Brain perfusi dengan dan tanpa kontras dan juga tambahan 3D navigasi yang digunakan untuk navigasi tumor oleh dokter bedah. Namun dengan banyaknya sekuen yang digunakan pemeriksaan MRI brain perfusi pada ksus tumor cukup memakan waktu yang lama. Oleh Karen itu dibutuhkan suatu optimalisasi pada sekuen-sekuen yang digunakan.

2. Peranan dari penerapan MR Perfusi dengan metode Arterial Spin Labelling (ASL) dan metode Dynamic Susceptibility Contrast (DSC) dalam penegakan diagnosa tumordi Rumah Sakit Pusat Otak Nasional
Menurut hasil observasi dan wawancara dengan responden dokter spesialis radiologi, MRI merupakan modalitas utama untuk pemeriksaan pasien tumor. Dengan MRI dokter mampu memperoleh banyak informasi mengenai kasus tersebut diantaranya mampu membedakan jenis tumor, mengevaluasi batas tumor, dan mengevaluasi pembuluh darah. Sehingga pemeriksaan MRI brain menjadi hal yang terpenting dalam penegakan diagnose.

Menurut Chysikopoulus HS (2009) citra MRI diperlukan untuk memberikan gambaran awal tipe tumor, lokasi, ukuran, karakterisasi, staging, dan struktur di sekitar tumor, perencanaan terapi dan pemantauan hasil terapi. Citra T1WI post contrast memberikan gambaran batasan tumor . lemak dan tumor yang menyerap media kontras paramagnetik menghasilkan sinyal yang tinggi, padahal tumor dapat berlokasi di jaringan-jaringan yang mengandung lemak seperti di bone marrow, retro orbita, maupun lokasi-lokasi lainnya sehingga berpotensi menyebabkan gambaran dengan batasan tumor yang kurang jelas.

Menurut penulis, Pemeriksaan MRI bertujuan mengetahui karakteristik morpologik yaitu lokasi, ukuran, bentuk, perluasan dan lain lain dari keadaan patologis. Tujuan tersebut dapat diperoleh dengan menilai salah satu atau kombinasi gambar penampang tubuh akial, sagittal, koronal atau oblik tergantung pada letak organ dan kemungkinan patologinya. Pemeriksaan MRI brain menjadi salah satu langkah efektif dalam menegakan diagnose tumor dimana tumor juga merupakan salah satu jaringan lunak dan MRI menjadi modalitas yang bagus juga dalam pencitraan jaringan lunak. Dengan MRI, radiolog dapat memberikan diagnosis tumor otak dan organ normal dari sisi medis. Secara spesifik kelebihan MRI dibandingkan dengan pemeriksaan CT Scan bahwa MRI lebih unggul untuk mendeteksi beberapa kelainan pada jaringan lunak seperti otak.

Dalam mendiagnosa patologi tumor, Instalasi Radiologi Rumah Sakit Pusat Otak Nasional menggunakan sekuen MR perfusi dengan metode Dynamic Susceptibility Contrast (DSC) dan Arterial Spin Labelling (ASL). MR perfusi tentunya menjadi salah satu sekuen yang sangat membantu dalam memberikan informasi terkait patologi diantaranya dapat mementukan ukuran tumor, melihat batas tumor, batas edema, dan jenis tumor yang diderita. Tentunya dalam pelaksanaan rutin yang dilakukan untuk pasien tumor sendiri akan dilakukan pemeriksaan MRI dengan beberapa sekuen sesuai permintaan dokter radiolog. sekuen-sekuen tersebut saling melengkapi dalam memberi informasi. Untuk pasien tumor ini, akan dilakukan MR perfusi dengan kontras dan tanpa kontras.

Menurut Jahng et al (2014) MRI perfusi dapat dilakukan dengan beberapa metode sehingga dapat 
menampilkan nilai perfusi suatu jaringan, akan tetapi metode-metode tersebut memiliki perbedaan. Metodemetode tersebut diantaranya ialah Dynamic Susceptibility Contrast (DSC) dan Dynamic Contrast Enhancement (DCE) yang merupakan metode pemeriksaan MRI perfusi dengan menggunakan bahan media kontras positif dan ditemukan metode baru dalam pemeriksaan MRI perfusi tanpa menggunakan bantuan bahan media kontras positif seperti GdDTPA. Metode tersebut ialah Arterial Spin Labeling (ASL)

Menurut Radiografer, ASL merupakan metode perfusi tanpa kontras yang lebih aman karena no ionisasi dan no contrast agent, mudah dilakukan karena tidak ada persiapan khusus yang harus dilakukan pasien. Sedangkan menurut dokter radiolog, MR perfusi dilakukan dengan dan tanpa kontras untuk tujuan masing-masing.

Arterial Spin Labelling (ASL) merupakan metode rutin pada MRI brain perfusi dengan kasus tumor yang dilakukan di Instalasi Radiologi Rumah Sakit Pusat Otak Nasional. Penggunaan metode ini digabungkan dengan penggunaan metode perfusi yang lain yaitu Dynamic Susceptibility Contrast (DSC). Di Instalasi Radiologi Rumah Sakit Pusat Otak Nasional penginjeksian media kontras dilakukan oleh perawat radiologi secara manual dan tanpa menggunakan automatic injector. Hasil yang diperolah dari MR perfusi salah satunya adalah nilai Cerebral Blood Flow (CBF). Nilai dari CBF merupakan salah satu parameter yang terdapat pada pemeriksaan perfusi (baik CT scan maupun MRI). CBF adalah jumlah aliran darah yang disuplai dari jantung ke otak. Nilai ini akan dilihat menggunakan grafik.

Menurut Lehmann et al. (2010)pada umumnya Cerebral Blood Volume (CBV) saat ini dinilai menggunakan metode DSC, sedangkan CBF akan dinilai menggunakan perfusi ASL yang memiliki kegunaan sebanding dalam diagnosis tumor, penilaian, dan tindak lanjut tumor serta pengobatan. Teori lain yang bersumber dari Grade (2015) menyebutkan bahwa ASL dalam pencitraan tumor otak menunjukkan korelasi yang tinggi antara area peningkatan $\mathrm{CBF}$ yang diukur dengan ASL dan peningkatan volume darah otak (CBV) yang diukur dengan pencitraan DSC atau DCE MRI.

Menurut dokter radiolog, dari segi informasi yang diperoleh DSC tentu lebih unggul dalam memberikan informasi terkait parameter perfusi karena dalam penggunaan DSC maka radiolog akan mendapatkan nilai Cerebral Blood Flow (CBF), Cerebral Blood Volume (CBV), Mean Transit Time (MTT), dan Time To Peak (TTP). Akan tetapi diperlukan tekanan dan flow rate yang konstan dan terstandar dalam pemasukan media kontras yang disuntikan melalui intra vena. Hal ini yang menyebabkan terkadang hasil dari grafik CBF yang akan dinilai kurang baik.
Dengan adanya metode ASL tentu mampu memberi tambahan informasi terkait dengan nilai CBF yang diperoleh. Kekurangannya pada metode ASL radiolog hanya mampu memperoleh satu informasi saja.

Menurut penulis tentu setiap metode mempunyai kelebihan dan kekurangan masing-masing. Apabila melihat dari kondisi lapangan yang terjadi di Instalasi Radiologi Rumah Sakit Pusat Otak Nasional kedua metode ini sama-sama bisa dilakukan terhadap pasien. Kecuali pada pasien dengan kontras indikasi tertentu (renal failure). Meskipun demikian penggunaan kedua sekuen ini secara bersamaan tentu akan menambah waktu pemeriksaan yang cukup lama. Hal ini bisa sangat berpengaruh pada pasien yang tidak kooperatif. Apabila merujuk pada beberapa teori terbaru dalam salah satu jurnal yang ditulis oleh Pungavkar dan Rama berjudul Arterial Spin Labelling: A novel promising perfusion technique - can it be replacement to dynamic susceptibility contrast MRI? Dapat dilihat penjelasan dalam teori tersebut bahwa Skor ASL lebih baik dibandingkan MRI DSC karena dapat mengukur nilai absolut dan tidak dipengaruhi oleh permeabilitas, yang merupakan faktor perancu utama dalam DSC. Dari penjelasan tersebut menunjukan bahwa dengan berbagai penelitian yang akan terus dilakukan metode ASL mampu menggantikan pemeriksaan MR perfusi dengan kontras yaitu metode DSC.

Menurut Radiolog, metode ASL menjadi metode yang belum sepenuhnya reliable dan terstandarisasi. Alasan inilah yang menjadikan metode ini masih jarang digunakan untuk pemeriksaan MR Perfusi khususnya pada berbagai klinis Neurovascular disease.

Menurut radiografer, ASL mempunya berbagai kelebihan diantaranya non-invasive, lebih mudah digunakan lebih cepat dan tidak memerlukan media kontras. Hal tersebut juga sesuai dengan pernyataan dari dokter radiolog yang menyebutkan bahwa pemeriksaan brain dengan menggunakan ASL ini tidak memerlukan standarisasi penyuntikan sehingga akan menghasilkan grafik CBF yang lebih baik untuk dinilai.

Menurut Pungavkar dan Rama (2017) metode Ini memberikan manfaat dalam banyak bidang klinis terutama pada pasien dengan gangguan fungsi ginjal dan pada mereka yang melakukan pemeriksaan berlanjut dan berulang. ASL ini juga membantu follow up screening bagi pasien setelah kemo terapi, pada pasien anak anak dimana kemungkinan akan sulit ditemukan akses untuk penyuntikan media kontras pada vena. Pemrosesan data dalam ASL 3D bersifat otomatis dan tidak memerlukan input ahli radiologi atau fisikawan dalam sebagian besar kasus. ASL sangat berguna dalam keseluruhan penilaian tumor otak, baik dalam pengaturan pra dan pasca operasi - untuk menilai tumor, untuk melokalisasi situs biopsi, untuk menilai aktivitas neoplastik 
residual pasca operasi, untuk membedakan rekurensi dan perubahan pasca perawatan, untuk menilai kemanjuran metode pengobatan yang lebih baru seperti obat anti angiogenik, dan juga untuk menilai penumbra iskemik pada pasien dengan stroke akut. ASL lebih unggul dalam menilai limfoma bila dibandingkan dengan DSC

Menurut penulis ASL merupakan metode terbaru yang sejauh ini masih dalam proses penelitian walaupun memang sudah banyak diaplikasikan dalam bidang klinis. Dengan munculnya metode baru dengan berbagai teknik yang dapat dialkukan tentunya pasti akan membantu proses penegakan diagnosis, salah satunya metode ASL ini. Sejauh ini metode ASL masih dalam proses pengembangan dan disebutkan bahwa metode ini still under research atau masih terus dilakukan penelitian untuk penyempurnaan. Meski demikian dengan banyaknya temuan-temuan baru metode ini akan menjadi salah satu metode yang aplikatif. Dengan berbagai kelebihan yang dimiliki ASL yang didasari dengan tidak menggunakan media kontras menjadi metode yang aman digunakan di semua jenis pasien, meski demikian tentu walaupun tidak digunakan dengan media kontras metode ini diharapkan tetap mampu mengcover parameter perfusi yang mendukung image quality. Dengan tingginya tingkat prevalansi tumor dan dilakukannya treatment post surgery seperti kemoterapi yang jelas pasti menggunakan banyak radiasi dan pasien mendapat banyak paparan radiasi metode ini menjadi salah satu alternative pula dalam menilai perfusi pada MRI. Karena dengan kemampuan no contrast agent dan non ionisasi pemeriksaan dengan metode ini dapat meningkatkan keamanan untuk pasien dan mengurangi dosis media kontras yang masuk pada tubuh pasien. Selain itu dengan pemroses otomatis yang dilakukan oleh ASL akan meningkatkan tingkat keakurasian terhadap suatu informasi yang didapat karena tidak akan terpengaruh dengan permeability yang nantinya akan mengganggu informasi citra.

Menurut dokter radiolog, pemeriksaan dengan ASL yang menggunakan basic sequence FSE juga akan memberikan keuntungan bagi klinisi. Pada perfusi apabila pasien dengan klinis tumor vaskularisasi biasanya akan timbul artefak. Hal ini akan mengurangi tingkat akurasi atau validitas dari informasi yang didapat. Akan susah bagi radiolog untuk membedakan apakah ada pendarahan atau tidak pada tumor tersebut.

Menurut Pungavkar dan Rama (2017) ASL memiliki keuntungan yaitu ketidaksensitifan untuk melihat variasi susceptibility yang disebabkan karena hemorage setelah intervensi pasca operasi.

Menurut penulis jika melihat dari pernyataan yang disampaikan oleh radiolog dengan teori yang menyebutkan ketidaksesnsitifan untuk melihat variasi susceptibility tentu hal ini akan membuat ASL menjadi metode yang lebih unggul dari DSC. Melihat basic sequence yang dimiliki oleh ASL yaitu FSE dimana FSE itu tidak sensitif yang artinya apabila terdapat pendarahan kemudian digunakanlah metode ASL maka tidak akan terjadi artefak pada gambar yang dihasilkan. Hal ini berbeda dengan DSC yang menggunakan basic sequence EPI dan menggunakan media kontras. Jika membicarakan tentang EPI yang digunakan dalam perfusi di Rumah Sakit Pusat Otak Nasional, EPI akan menyebabkan artefak pada gambar dengan klinis tumor yang didalamnya terdapat vaskularisasi atau pendarahan. Ketidak sensitifan yang dimaksud adalah tidak sensitif terhadap susceptibility artinya tidak rentan terhadap artefak yang terjadi. Hal ini sesuai dengan teori yang disampaikan Pungavkar dan Rama (2017) FSE bukan sensitif terhadap pendarahan tetapi tidak sensitif terhadap variasi susceptibility yang disebabkan karena pendarahan. Berarti apabila ada pendarahan saat itu, hal ini menjadi keuntungan untuk ASL karena gambar tidak akan terpengaruh oleh artefak. FSE jika dikenai pendarahan tidak akan mengganggu image quality. Artefak pendarahan yang ditimbulkan karena basic sequence EPI akan mempengaruhi nilai parameter perfusi. Dengan ASL apabila ada pendarahan dengan tumor tidak akan menyebabkan gangguan artefak, tidak menyebabkan gangguan flow karena tidak ada kepekaan terhadap susceptibility sehingga mampu dibedakan dengan tepat mana pendarhaan dan mana tumor. Hal ini membuat ASL kini semakin menjadi metode yang akurat.

\section{Simpulan}

1. Prosedur pemeriksaan MRI Brain Perfusi pada pasien tumor dimulai dari puasa 2 jam sebelum pemeriksaan, cek ureum kreatinin kemudian dihitung Glomerulo Filtration Rate (GFR) oleh petugas,mengisi informed consent, dan melakukan screening logam. Menggunakan posisi supine dengan titik sentrasi pada glabella. Sekuen yang digunakan yaitu Localizer,FLAIR, DWI, T1 Axial, T2 Coronal, SWI, dan ASL. Lalu dilanjutkan dengan injeksi media kontras dan scanning post kontras yang terdiri dari sekuenDSC, T2 Axial + C, dan T1 axial + C. Proses filming yang dicetak pada 4 lembar film ukuran 35 x 43 cm ditambah dengan $1 \mathrm{CD}$.

2. Masih dibutuhkan penerapan kedua metode MR perfusi yaitu metode ASL dan metode DSC. Metode ASL akan memberikan tambahan informasi berupa nilai absolut dari Cerebral Blood Flow yang tidak dipengaruhi oleh permeabilitas, selain itu metode DSC mampu memberikan nilai Cerebral Blood Volume yang digunakan sebagai parameter penilaian MR Perfusi di Instalasi Radiologi Rumah Sakit Pusat Otak Nasional.

\section{Daftar Pustaka}


Chysikopoulus HS. Clinical MRI Imaging and Physics: a Tutorial. Berlin; Springer. 2009; 43- 44

Elmaoglu, Muhammed, Celik, Azim. 2012. MRI Handbook MR Physics, Patient Positioning and Protocols. Springer-Verlag, New York.

Enggariani, S.Ked. 2008. Tumor Otak. Fakultas Kedokteran Universitas Riau. RSUD Arifin Achmad Pekanbaru.

Grade M, J.A Hernandez Tamames, F.B Pizzini, E. Achten, X.Golay, M Smith. 2015. A Neuroradiologist's guide to arterial spin labeling MRI in clinical practice. Neuroradiology; 57: 1181-1202

Jahng GH, Ka-Loh Li, Ostergaard Leif, Calamante Fernando, 2014, Perfusion Magentic Resonance Imaging: A Comprehensive Update on Principles and Techniques. Korean Journal of Radiology

Kartawiguna, D, 2015, Tomografi Resonani Magnetik Inti: Teori Dasar, Pembentukan Gambar dan Instrumentasi Perangkat Kerasnya. Graha Ilmu; Yogyakart

Laszlo M. Neuroimaging in neuro Oncology. Neuroimaging. Elsevier. 2009; 27-1

Lehmann P, Monet P, de Marco G et al (2010) A comparative study of perfusion measurement in brain tumours at 3 tesla MR: arterial spin labeling versus dynamic susceptibility contrast-enhanced MRI. Eur Neurol 64(1):21-26 144 .

Moller T.B danReif E. 2007.Pocket Atlas of Sectional Anatomy Computed Tomography and Magnetic Resonance Imaging. Germany:Thieme

Petersen E,T, I Zimine, Y-C L HO, X Golay, 2006, "noninvasive measurement of perfusion: a critical review of arterial spin labeling techniques", The British Journal of Radiology:697

Pungavkar, Sona A dan Rama Yanamandala. 2017. Arterial Spin labeling : A novel promising perfusion technique Can it be a replacement to dynamic susceptibility contrast MRI?. Neurology India

Rengachary SS, Ellenbogen RG. 2005. Principles of Neurosurgery 2nd Ed. Philadelphia : Elsiever

Wahjoepramono, E.J., 2006. Tumor Otak. 1-5. FakultasKedokteranUniversitasPelitaHarapanLippoKara waci. Jakarta

Westbrook C. 2014. Handbook of MRI technique, Fourth Edition, W. B.. Sounders Company, Canada

Wiemels, J, Wrensch, M, Claus, EB, 2010. Epidemiology and etiology of meningioma. J Neurooncol 99 (3): 307-14. 